\title{
Mechanisms of Pure Alexia: Spatially Based Impairment, Letter Identification Deficit, or Both?
}

\author{
Anne-Catherine Bachoud-Lévi ${ }^{1}$ and Paolo Bartolomeo ${ }^{2}$ \\ ${ }^{1}$ INSERM U. 421, Faculté de Medecine, Paris XII, and Unité de Neuropsychologie, Département de Neurosciences \\ Médicales du CHU Henri Mondor, AP-HP, Créteil, France and ${ }^{2}$ INSERM U. 324, Paris, France
}

\begin{abstract}
We studied reading performance for words and for isolated letters in a pure alexic patient. She performed reasonably well when naming isolated letters but was slower in reading letters than a control subject when reaction times (RTs) were recorded. When the patient read isolated letters, RTs were slower for a subset of letters that cannot be recognized from their left part alone (e.g. "b", an ambiguous letter, could be read " $b$ " " $h$ " "l" or "k" whereas " $a$ " has no predictable confounders). We observed a significant positive correlation between the RTs for reading a word and the mean RTs for reading each of its composing letters before its uniqueness point (i.e. the point, when reading from the left to the right, where a word cannot be a word other than the one it is). This result suggests that, in our patient, the letter identification deficit can account for the slow, letter-by-letter reading behaviour, insofar as each letter represents a perceptual problem. Our findings can be accounted for by a deficit in the parallel processing of the left and right parts of each letter, compounded with a bias to process first the left part of the letter, and may thus reconcile the hypotheses of spatiallybased deficit (Rapp and Caramazza, 1991) and of a perceptual deficit occurring at the letter identification level (Behrmann and Shallice, 1995; Perri et al., 1996).
\end{abstract}

\section{Introduction}

Pure alexia, or letter-by-letter reading, ${ }^{1}$ is an acquired deficit following a lesion of the left occipital brain region in righthanded patients. Reading performance in these patients is characterised by a "word length effect", an abnormal slowing down of reading as a function of the number of letters of the word. Two accounts, both based on the hypothesis of a prelexical deficit (i.e. a deficit prior to the activation of the word's lexical entry), have been proposed to explain the relationship between the word length effect and patient reading abilities in pure alexia. Rapp and Caramazza (1991) explained the letterby-letter behaviour of their patient, HR, in terms of a spatially determined deficit, characterised by a left-to-right gradient of processing efficiency. HR's accuracy decreased across the letter positions in the letter string. According to the authors, attentional resources must be allocated sequentially to each letter location. Hence, the redistribution of attention across spatial locations costs time that results in the word length effect. This deficit was considered different from unilateral spatial neglect, in that HR did not show signs of right neglect on tests of copying, line cancellation or line bisection, nor did she produce reading responses typical of "neglect dyslexia". Chialant and Caramazza (1998) obtained a similar pattern of results with their patient, MJ.
On the other hand, Behrmann and Shallice (1995) argued for a nonspatial perceptual deficit in the activation of individual letters disrupting their rapid identification. Behrmann and Shallice denied any spatially-based deficit in their patient, DS, and argued that letters appearing to the right of other letters are more subject to error because of their order of presentation and not because of a spatial bias. Similarly, other authors argued for a letter identification deficit in alexia (Bub et al., 1989; Arguin and Bub, 1993). Nevertheless, the relationship between the letter identification deficit and the reading disorder remains controversial (see Johnston and McClelland, 1980; McClelland and Rumelhart, 1981; Patterson and Kay, 1982; Friedman, 1988; Howard, 1991). Indeed, a general problem with these studies is that the deficits (spatial gradient, letter processing disorder) were observed in individual patients, and the relationship between these deficits and alexia was not explicitly investigated.

In an attempt to understand the relationship between alexia and visual processing impairment in their patient TU, Farah and Wallace (1991, Exp. 2) demonstrated that the reading time was related to the poor visual quality of the word. Perri et al. (1996) described a pure alexic patient, SP, who produced similar reading errors on letters presented both in isolation 
and in words. In both letter and word reading, perceptual errors were prevalent: SP, like Patterson and Kay's (1982) patients, exhibited a tendency to confuse structurally similar letters (e.g. b-p, b-d, q-g). Perri et al. proposed an account of pure alexia based on a deficit in accessing the abstract visual representations of letters. Such a deficit would prevent efficient letter identification, thereby forcing the patient to resort to a letter-by-letter reading. Consistent with this interpretation, in their review of the literature, Behrmann et al. (1998) found that virtually all published reports of pure alexia contained either some evidence of a letter identification deficit, or no evidence against it. $^{2}$

In this study, we describe a letter-by-letter reader who produced only very occasional errors when reading letters in isolation but who was slowed in letter naming when RTs were recorded. Madame D was slower when reading letters whose left part does not allow their unambiguous identification. This suggests that her letter identification deficit had a spatial component. Moreover, we found evidence of a relationship between the time required to read individual letters and the time required to read words, suggesting that her letter processing deficit, though very mild on free vision reading, can account for her alexia. These results may reconcile the hypothesis of a spatially-based deficit and that of a letter identification deficit in letter-by-letter reading.

\section{Case report}

Madame D, a 74-year-old, right-handed retired secretary, was hospitalised in May 1995 after the sudden occurrence of headaches and visual disturbances. On admission, the patient presented a right homonymous hemianopia. Her reading was slow and letter-by-letter, with occasional confusion among letters. Writing was presented. She showed a mild anomia, without any comprehension or repetition deficits. CT scan revealed a left temporo-occipital haematoma.

A few weeks later, she had recovered from her anomic deficit, and could perfectly name 40/40 black and white pictures from the DO80 (Deloche et al., 1996). Her only complaint was the persisting reading difficulty, although she felt she was able to read slightly faster than just after her stroke. Reading words and non words was laborious but feasible with numerous self-corrections, resulting in a perfect score of 30/30. Oral spelling was quick and accurate (30/30 correct). Madame D was flawless on a battery of tests of unilateral neglect (Bartolomeo and Chokron, 1999), on the Visual Object and Space Perception Battery (Warrington and James, 1991) and on the Judgement of Line Orientation Task (28/30 correct) (Benton et al., 1975). She had a global IQ of 116, as measured by the Raven Progressive Coloured Matrices (Raven et al., 1978). Verbal IQ and Performance IQ were respectively 115 and 93 on the WAIS-R (Wechsler, 1981). Memory IQ was 111, as assessed on the Wechsler Memory scale. Her digit span was 6 forward and 4 backward.

An MRI performed in Sep. 1995 showed a reduction in the size of the haematoma, which involved Brodmann's areas 18,
19 and 37. Experimental sessions began in July 1995, 2 months after lesion occurrence. At this time, visual fields appeared normal on clinical examinations. Goldman perimetry, however, showed the persistence of a mild visual field defect. This deficit, situated between $3^{\circ}$ and $15^{\circ}$ for the left eye and $2^{\circ}$ and $25^{\circ}$ for the right eye, was apparent only with the II test, and thus allowed some residual visual processing.

Unfortunately, in December 1996 Madame D suffered from a second, mirror-image, hemorrhagic lesion (see Bartolomeo et al., 1998b), after which she became achromatopsic, prosopagnosic and object agnosic. This occurrence brought to an end our testing sessions on her pure alexia.

\section{Free-vision word reading}

\section{Materials and procedure}

Two 100-word lists were used. Each consisted of groups of 20 words of 4, 5, 6, 7 and 8 letters in length. The lists were matched for frequency: Half of the stimuli were high-frequency words [ $>30$ per million from the Brulex database for French word counts for list I and $>50$ for list II (Content et al., 1990), half were low-frequency words ( $<4.5$ for list I and $<13$ for list II). The words, printed in lower case on a paper strip, were presented free field for an unlimited amount of time. Accuracy and reading time were recorded manually by the examiner, who started a stopwatch upon stimulus presentation and stopped it when the response was complete. Each of the two word lists was presented twice on separate occasions.

\section{Results}

Madame D correctly read aloud 398/400 (99\%) words, with few self corrections. Although she felt she was able to read slightly faster than immediately after the stroke, she was still distressed by her reading difficulties. An ANOVA with time to complete reading as the dependent variable, and word length (number of letters: 4 to 8 ) and lexical frequency (high vs. low) as factors was carried out. The ANOVA demonstrated an effect of length $[\mathrm{F}(4,388)=6.97, P<0.0001]$, because longer words were read slower than shorter words, and an effect of frequency $[\mathrm{F}(1,388)=10.74, P<0.005]$, because high-frequency words were read faster than low-frequency words. These effects interacted $[\mathrm{F}(4,388)=2.77, P<0.05]$, because reading times increased with length more for low-frequency words (slope, $0.66 \mathrm{sec}$ per additional letter) than for high-frequency words (slope, $0.19 \mathrm{sec}$ ) (Table 1). Word reading time correlated with word length $[\mathrm{r}=0.23, \mathrm{Z}=4.70, P<0.0001]$.

Table 1. Mean correct reading times (in secs) for high- and low frequency words of various length

\begin{tabular}{llllll}
\hline Word length (letters) & 4 & 5 & 6 & 7 & 8 \\
\hline High frequency & 2.23 & 2.69 & 2.30 & 3.00 & 3.00 \\
Low frequency & 2.18 & 2.47 & 3.42 & 5.00 & 4.24 \\
\hline
\end{tabular}




\section{Discussion}

Although Madame D's reading deficit was relatively mild, her reading time for words increased with the number of letters. This length effect is within the range reported previously for letter-by-letter readers (see Shallice, 1988, Table 4.1, p. 74). The effect of lexical frequency on word reading latencies can be explained in the framework of a hierarchical model of reading (McClelland and Rumelhart, 1981) as a top-down effect; word nodes for high-frequency words have higher resting levels than nodes for low-frequency words, and can thus be activated more easily in the presence of weak or ambiguous input from more peripheral levels of analysis (see Perri et al., 1996; Behrmann et al., 1998). However, one might also argue that a guessing strategy would apply more strongly to frequent words than to rare words, and thus is not necessary to posit a model of lexical access to explain the interaction between frequency and length in word reading.

\section{Free-vision letter reading}

Madame D was presented with 156 lower-case letters in isolation (6 times the French alphabet), in a random order. The letters were printed in Times 12 font, in the centre of a $21 \times 3 \mathrm{~cm}$ horizontal sheet of paper, located $30 \mathrm{~cm}$ from her eyes. Madame D read all of the letters rapidly and effortlessly. She produced five errors $(3.2 \%)$, which were immediately self-corrected. The errors were $\mathrm{j} \rightarrow$ "i", $1 \rightarrow$ "i" (twice), $\mathrm{x} \rightarrow$ " $\mathrm{k} ", \mathrm{f} \rightarrow$ "g". The low error rate and spontaneous selfcorrections indicate that, like patient DS (Behrmann and Shallice, 1995), Madame D could identify single letters in the absence of time constraints with a reasonable degree of accuracy.

In summary, Madame D's reading was relatively accurate but slow. In particular, her word reading time increased with word length, the defining feature of letter-by-letter reading. She claimed that she could not identify a word unless she had recognised each of its component letters. Nevertheless, in sentence reading, she tried to guess the word without having identified all of the letters. As a consequence, Madame D produced many more errors ${ }^{3}$ (though some were self-corrected) than in word reading and was totally discouraged by her performance.

\section{Experimental investigations}

\section{Experiment 1: Letter detection in horizontal strings}

Madame D reads single letters relatively well, but her reading is impaired for words, which are visual objects consisting of several letters, and even more for sentences. Could this discrepancy result from an inability to rapidly process multi-item objects? According to earlier accounts of pure alexia, a reading disorder may result from a reduction of the attentional angle in which simultaneous processing of multiple items can be performed (Kinsbourne and Warrington,
1962). To test for this possibility, we asked Madame D to identify two letters presented at the opposite ends of a string of digits (e.g. Z54278P or Q674W) (see Warrington and Shallice, 1980, Experiment 1). To avoid the potential effects of the hemianopic scotoma, all the stimuli were given in the left hemifield.

\section{Materials and procedure}

Seventy-eight horizontal strings of digits were constructed. Each string was flanked by two upper case letters, in 18-point Helvetica Font, on the right and the left side of the string. There were three possible string lengths, 3, 5 and 7-digit, with 26 strings for each length.

A 1000 msec blank screen preceded the appearance of the fixation point (a cross) in the centre of the screen. After fixation on the cross, the patient pressed a button to make it disappear. Then, a $150 \mathrm{msec}$ blank screen preceded the presentation of a string. The string appeared for $100 \mathrm{msec}$. Strings were presented horizontally, at random, and no string type was presented more than three times in succession. The centre of each string was $3^{\circ}$ to the left of the centre of the fixation point, with the rightmost letter appearing at about $0.7^{\circ}-1.4^{\circ}$ left of fixation (depending on the string length). To exclude an influence of memory load, in half of the trials Madame D had to report the left-sided letter first and in the other half she had to report the right-sided letter before the left-sided one. The order of left-first and right-first blocks was alternated with each session. The experiment was repeated seven times in separate sessions.

\section{Results and discussion}

There was no significant difference in the overall accuracy as a function of the order of report (left letter first: 33\%; right letter first: $\left.29 \% ; \chi^{2}(1)=2, P>0.1\right)$. Thus, the data from the two conditions were pooled together (see Table 2). Madame D reported 342/1092 (31.3\%) letters correctly with better performance for the left- than for the right-sided letter of the string $\left[\chi^{2}(1)=268, \mathrm{P}<0.0001\right]$. For left-sided letters, there was no effect of the number of intervening digits $\left[\chi^{2}(2)=2.97, \mathrm{P}>0.1\right]$. For right-sided letters, the string type tended to influence performance $\left[\chi^{2}(2)=5.67, \mathrm{P}=0.06\right]$, due to a marginally greater accuracy for 5-digit strings than for the other strings. Madame D's performance in reading the rightsided letters was, however, equally impaired for the 3 - and the 7-digit strings $\left[\chi^{2}<1\right]$.

Table 2. Accuracy (number of correct responses) as a function of the position of the letter and of the number of intervening digits for Experiment 1

\begin{tabular}{lclll}
\hline & 3-digit & 5-digit & 7-digit & Total \\
\hline Left letter & $108 / 182(59 \%)$ & $92 / 182(51 \%)$ & $97 / 182(55 \%)$ & $297 / 546(54 \%)$ \\
Right letter & $13 / 182(7 \%)$ & $22 / 182(12 \%)$ & $10 / 182(5 \%)$ & $45 / 546(8 \%)$ \\
\hline
\end{tabular}


Despite a left hemi-field presentation of the stimulus, the consistent advantage for left-sided letters over right-sided letters might result from a spatial bias in which left-sided details are processed better than right-sided details (see Rapp and Caramazza, 1991). The alternative explanation, that the left-over-right advantage stems from a general reduction of the perceptual span, seems to be ruled out by the finding that performance was independent of the number of intervening digits.

\section{Experiment 2: Letter detection in vertical strings}

To assess whether the left superiority effect really depended on a spatially-based mechanism or on a general advantage of the first processed stimulus, in this experiment we presented similar strings, but vertically arranged. If the effect depended on a processing bias in the horizontal dimension, no difference between the two positions should be observed (see Caramazza and Hillis, 1990; Rapp and Caramazza, 1991).

\section{Methods}

Fifty-two stimuli similar to those of Exp. 1, but vertically arranged, were constructed. For each item, two upper-case letters were positioned one directly above and one below a digit. Each item was about $2^{\circ}$ high. Stimuli were presented vertically $3^{\circ}$ to the left of fixation in 18-point Helvetica Font. The experiment was repeated two times in the same session. Madame D was asked to report the upper letter first and the lower letter second in half of the trials, and in the other half to report first the lower letter. In all other respects, the procedure was the same as for Exp. 1.

\section{Results}

There was no significant difference in accuracy of letter report as a function of order of report (upper letter first: 73\%; lower letter first: $\left.77 \%, \chi^{2}(1)=2, P>0.1\right)$. Thus, again, the data from the two conditions (upper letter or lower letter first) were pooled and are reported together. No differences in accuracy were recorded for upper letters (75/104 letters, or 72\%) as compared to lower letters $(81 / 104$ letters, or $77 \%), \chi^{2}<1$.

\section{Discussion}

Results of Experiments 1 (left superiority when reporting letters in horizontal strings) and 2 (no difference in performance for similar strings but arranged vertically) indicate an horizontal asymmetry of performance in Madame D. These results are similar to those described by Rapp and Caramazza (1991) and Chialant and Caramazza (1998). However, even at the leftmost side of the string, Madame D's performance did not exceed 57\% correct for horizontal strings in Experiment 1. Despite Madame D's relatively good performance in single letter reading, this suggests a problem in identifying letters independent of their spatial position.

\section{Experiment 3: Letter naming latencies}

Many, but not all, letter-by letter readers are impaired in letter identification under free exposure conditions (see Behrmann et al., 1998, for a review). Some are impaired only when letter identification is performed under conditions of tachistoscopic exposure (Levine and Calvanio, 1978) or when several letters are presented simultaneously (Kinsbourne and Warrington, 1962; Warrington and Shallice, 1980; Reuter-Lorenz and Brunn, 1990; Kay and Hanley, 1991). Often, investigation of letter processing used accuracy, and not RT, as the dependent variable. When a chronometric constraint is introduced, most, and possibly all, letter-by-letter readers seem to demonstrate a deficit in tasks involving letter identification (see Behrmann et al., 1998). When tested in free time exposure, Madame D did not demonstrate a severe impairment in letter identification; the assessment of her reading RT for letters might, however, show a subtler deficit.

\section{Apparatus}

Letters were presented on the plasma screen of a Toshiba T5200 computer. A microphone was connected to an OROS AU-22 digital board, that digitised the naming response $(8 \mathrm{~Hz}$, 16 bits) and ran a signal detection algorithm (using an adaptive threshold) which measured naming time to the nearest millisecond. Digitised responses were stored on a disk for subsequent scoring of errors. All experimental processing was controlled by Expe 3.2 software written by C. Pallier (see Pallier et al., 1997).

\section{Material and procedure}

Reading times for isolated letters were measured for Madame D and JD, a control subject matched for age, educational level and hand dominance (her 74-year-old, right-handed husband). All 26 letters of the French alphabet were used. The letters were presented lower-case in black 8 points Trip font (subtending a visual angle of about $1.50^{\circ}$ ) in the centre of the computer screen, against a white background. Madame D and JD were instructed to name the letter as soon as it appeared on the screen and to respond as fast as possible. The target letter remained visible until a vocal response was made or until five seconds had elapsed. Responses were followed by a 2 -sec blank screen before the next trial began. Naming latencies were measured from the appearance of the letter on the display to the onset of a response. The set of 26 letters was presented 4 times in each session, in a random order. The experiment was divided into two blocks. Each block contained twice the complete alphabet and was preceded by 13 practice trials. Three sessions were performed.

\section{Results and discussion}

The overall accuracy was similar for Madame D (94.55\%) and for JD $\left(98.56 \% ; \chi^{2}(1)=2, P>0.1\right)$. Reaction times corresponding to erroneous responses were excluded from the analyses. Mean naming latencies for letters are displayed 


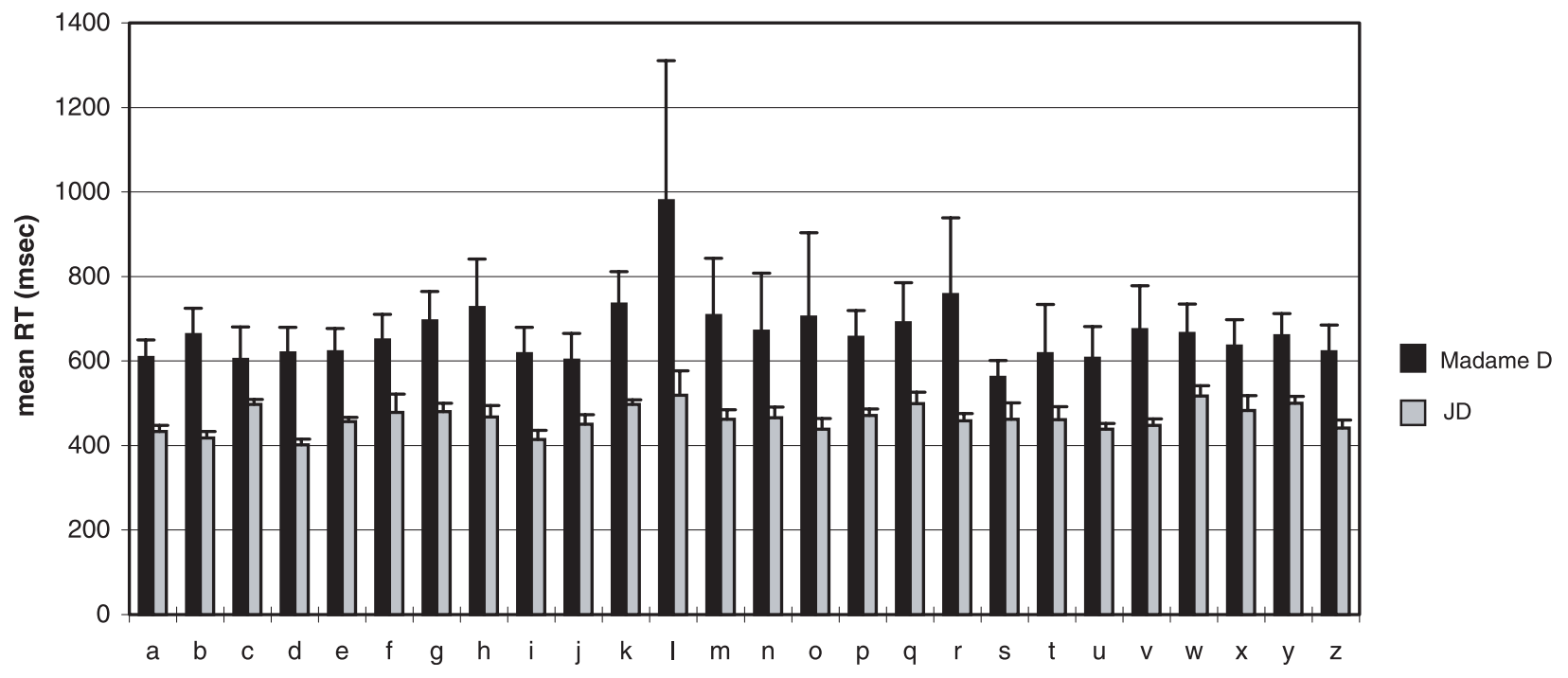

Fig. 1. Mean letter naming RT (in $\mathrm{msec}$ ) for Experiment 3.

in Fig. 1. Madame D was slower than JD in reading letters [respectively, mean RT, $696 \mathrm{msec}$; SD, $98 \mathrm{msec}$, and mean RT, $463 \mathrm{msec}$; SD, $30 \mathrm{msec}, \mathrm{t}(50)=11.54, P<.0001]$. A contribution of the partial scotoma to this slowing is unlikely, given that letters were presented within foveal vision, well outside the limits of the scotoma. The possibility remains that a general cognitive slowing due to the brain lesion influenced performance. In a control experiment, Madame $\mathrm{D}$ was instructed to press a bar as quickly as possible when among three horizontally arranged black circles, one of them became grey (Bartolomeo, 1997). Although she was slower with rightsided targets than with left-sided targets by $193 \mathrm{msec}$ $[\mathrm{t}(156)=-2.95, \mathrm{p}<.004]$, her performance with left-sided non alphabetic stimuli $(411 \mathrm{msec})$ was in the range of RTs obtained by 5 age-matched controls (mean 68 years, range 57-73 years; their RTs ranged between 378 and $566 \mathrm{msec}$ ).

Despite the fact that letters usually occupy a very small part of the visual field, they are spatially organized visual objects, with different features localized in different spatial regions. Indeed, clues to recognise letters are asymmetrically distributed in space, the most helpful features being often located on the right part of the letter (Kolers, 1969). Can these notions help reconcile accounts of pure alexia based on a spatially determined deficit (Rapp and Caramazza, 1991) with those based on a perceptual letter identification deficit (e.g. Behrmann and Shallice, 1995)? If a spatially-based deficit applies to letters, with better processing of the left part than of the right part, it should mainly affect processing of those letters whose right part is necessary to their identification. To explore this possibility, we split lowercase script letters (like the ones used in the present experiment) on the basis of their composing distinctive features. The left half part of the letters and their leftmost features were printed on a sheet of paper (for example, "b" was printed "l" or "b"). Seven control subjects (mean age: 35.9 years, all right-handed, 3 males and 4 females) were asked to complete the right part of the printed stimuli and to propose as many letters as they could. On the basis of controls' performance, we divided letters into two groups: "ambiguous" and "nonambiguous" letters. Ambiguous letters are those for which the left part does not allow an unambiguous identification and can yield at least two answers (e.g. "l" can yield to "l b k h") and "unambiguous" letters are those for which a single answer was provided (e.g., $\leq$ yields only to $\mathrm{z}$ ). Following the controls' performance, [b d p q $\mathrm{m} \mathrm{n} \mathrm{r} \mathrm{h} \mathrm{k} \mathrm{l} \mathrm{c} \mathrm{o} \mathrm{v} \mathrm{w]} \mathrm{were} \mathrm{defined} \mathrm{as} \mathrm{ambiguous}$ letters, [a e f g i j s t u x y z] as non ambiguous letters.

We re-analysed Madame D's performance in the present experiment using this dichotomy, and found that she was $103 \mathrm{msec}$ slower in reading ambiguous letters $(744 \mathrm{msec})$ than non ambiguous letters $(641 \mathrm{msec})$ [t(24) $=3.1, P=0.005$ ], while JD showed no difference between the two groups [respectively $468 \mathrm{msec}$ and $458 \mathrm{msec}, \mathrm{t}(24)<1$ ]. Madame D was slower than JD for both groups of letters when considered separately [ambiguous, $\mathrm{t}(26)=9.11, P<0.001$; non-ambiguous, $\mathrm{t}(22)=12.63, P<0.001]$. Interestingly, despite the absence of effect of letter ambiguity in JD, RTs in Madame D and in JD were correlated (regression analysis: $\left.\mathrm{r}^{2}=0.20, \mathrm{~F}(1,24)=6.14, P=0.02\right)$. This might indicate a similar trend of performance in normal subjects, amplified in letter-by-letter reading.

\section{Experiment 4: Letter naming latencies with lateralised presentation}

In principle, the partial right scotoma might contribute to Madame D's impaired performance. Although we deem it unlikely that the scotoma affected isolated letter naming (letters extended to $1.3^{\circ}$ from the centre in Experiment 3 and the scotoma from about $2^{\circ}$ to $25^{\circ}$ to the right), we designed an additional experiment as a control for the possible 
confounding effect of the scotoma. Letters were presented at random in three possible positions of the right or left hemifield, briefly enough to prevent the initiation of saccades. In addition, the spatial uncertainty about target localisation excluded the possibility of anticipatory eye movements.

\section{Methods}

Ten letters (a, c, h, k, m, q, s, t, u, z) were selected. Each letter was presented two times in six different positions, at $-5.5^{\circ}$, $-8^{\circ},-11.5^{\circ}$ to the left and at $+5.5^{\circ},+8^{\circ},+11.5^{\circ}$ to the right of the fixation point. Letters were displayed in a black 8 point trip font sustaining a visual angle of $1.5^{\circ}$. Three sessions were performed. Letters were presented in two blocks. Each letter was presented three times in each position for each block. Apparatus was the same as for Experiment 3. Madame D was instructed to name each letter as quickly as possible. A fixation cross was displayed in the centre of the screen for $500 \mathrm{msec}$, followed by a $300 \mathrm{msec}-$ blank screen. The letter was then displayed for $150 \mathrm{msec}$. After response, a $2 \mathrm{sec}$ pause preceded the onset of the following trial (including $4 \mathrm{sec}$ of time-out). Reaction times and accuracy were recorded as in the previous experiment.

\section{Results and discussion}

Because there was no significant difference in Madame D's performance between sessions, the results of the three sessions were analysed together. Results are displayed in Table 3. ANOVAs were conducted on naming latencies and errors. Letter location was the within-subject factor. Reaction times corresponding to the production of erroneous letters, stuttering, respiration, self correction or technical malfunction $(29.5 \%)$ were excluded from the analyses. Letter location consistently influenced RTs $[\mathrm{F}(5,40)=19.6, P<0.001]$. In the restricted analysis comparing the three left positions and the three right positions, letters were named faster in the left hemifield $(642 \mathrm{msec})$ than in the right hemifield $(918 \mathrm{msec})$ $[\mathrm{F}(1,8)=53.9, \mathrm{P}<0.0001]$ but there was no effect of the location of the letter within each hemifield $(\mathrm{F}<1)$. Analyses of errors yielded similar results. Accuracy was better in the left hemifield $(93.7 \%$ correct) than in the right hemifield $(48.8 \%$ correct $)[\mathrm{F}(5,40)=61.4, P<0.001]$, presumably because the partial scotoma impaired reading performance in the right visual field. ${ }^{4}$

When analysed in terms of letter ambiguity, results of Experiment 4 also suggested a possible role of a spatially determined factor in Madame D's defective identification of letters. Ambiguous letters yielded similar latencies as non ambiguous

Table 3. Mean letter naming RT (in $\mathrm{msec}$ ) and percentage of errors for Experiment 4

\begin{tabular}{lllllll}
\hline & \multicolumn{6}{l}{ Visual angle } \\
\cline { 2 - 7 } & $-11.5^{\circ}$ & $-8^{\circ}$ & $-5.5^{\circ}$ & $+5.5^{\circ}$ & $+8^{\circ}$ & $+11.5^{\circ}$ \\
\hline RT (m sec) & 676 & 631 & 619 & 883 & 895 & 975 \\
Errors (\%) & 6.7 & 5.0 & 8.3 & 48.3 & 53.3 & 55 \\
\hline
\end{tabular}

ones $(\mathrm{F}<1)$, but there was an interaction between letter ambiguity and the locus of presentation $[\mathrm{F}(5,40)=4.6$, $P=0.002]$. This interaction resulted form the fact that RTs for ambiguous letters were longer than for non-ambiguous letters in the left hemifield, unaffected by the scotoma $[\mathrm{F}(1,8)=10.8, P=0.01]$, but not in the right hemifield $(\mathrm{F}<1)$. Analyses of errors yielded similar results. Ambiguous letters were less accurately identified than non ambiguous ones $[\mathrm{F}(1,8)=6.42, P=0.03]$. The interaction between ambiguity and location did not reach significance $[\mathrm{F}(5,40)=1.7, P>0.1]$. Thus, the results of Experiment 4 confirm that letter ambiguity slows down Madame D's reading, independently of the right hemianopic scotoma.

\section{Experiment 5: Upper case letter naming}

If a spatially-based effect of letter ambiguity influences Madame D's performance, it should also be present for orthographic material different in shape from lower-case letters. To test this notion, upper-case letters were used in the next experiment.

Experiment 5 followed the procedure of Experiment 3, with the following exceptions: The 26-letter alphabet was presented in upper case; letters were presented four times per session and there were four separate sessions. JD was not tested in this experiment.

To classify ambiguous and non-ambiguous letters, letters were again split into their two halves (vertically by the middle) and their left part was printed. Six control subjects (mean age: 31.8 years, all right-handed, 2 males and 4 females) were asked to propose as many letters as they could by completing the right side of the printed stimuli. Letters were classified as in the previous experiments as ambiguous when their left part did not allow their unambiguous identification (BCDEFGHIKLMNOIPQRVW), or as non-ambiguous when controls provided a single response (AJSTUXYZ).

\section{Results and discussion}

Accuracy was $97 \%$. Results were similar to those for lower case reading (mean RT, $645 \mathrm{msec}$; SD $58 \mathrm{msec}$ ). Ambiguous letters were named slower $(661 \mathrm{msec})$ than non-ambiguous ones $(608 \mathrm{msec}) \quad[\mathrm{t}(24)=2.6, \quad P<0.03]$. No effect was revealed by the analysis of errors $(t<1)$.

Madame D had similar RTs as when reading lower-case letters (Experiment 3). Once again, she was particularly slowed for ambiguous letters. The consistency between Experiments 3 and 5 supports the hypothesis of a role of an asymmetry in processing the spatial properties of letters in Madame D.

This asymmetry should in principle affect also the letters in vertical strings presented in Experiment 2. To assess this possibility, we re-analysed Madame D's performance in Experiment 2 using the ambiguous/non-ambiguous dichotomy for upper-case letters, ${ }^{5}$ and found that accuracy was poorer for ambiguous letters $(102 / 144$, or $71 \%)$ than for non ambiguous ones (54/64, or 84\%), Fisher's exact $P<0.05$. 
Table 4. Mean word naming RT (in $\mathrm{m} \mathrm{sec}$ ) and percentage of errors for Experiment 6

\begin{tabular}{|c|c|c|c|c|c|c|c|}
\hline & & \multicolumn{5}{|c|}{ Number of letters } & \multirow[t]{2}{*}{ Total } \\
\hline & & 4 & 5 & 6 & 7 & 8 & \\
\hline \multicolumn{8}{|l|}{ Madame D } \\
\hline \multirow[t]{2}{*}{ High frequency } & $\mathrm{RT}(\mathrm{m} \mathrm{sec})$ & 1365 & 1511 & 1135 & 1364 & 1549 & 1376 \\
\hline & Errors (\%) & 17 & 10 & 20 & 27 & 27 & 20 \\
\hline \multirow[t]{2}{*}{ Low frequency } & $\mathrm{RT}(\mathrm{m} \mathrm{sec})$ & 1165 & 1596 & 1815 & 1841 & 1585 & 1600 \\
\hline & Errors $(\%)$ & 43 & 30 & 30 & 27 & 43 & 35 \\
\hline \multirow[t]{2}{*}{ Total } & RT (m sec) & 1244 & 1553 & 1475 & 1603 & 1567 & 1488 \\
\hline & Errors $(\%)$ & 30 & 20 & 25 & 27 & 35 & 27 \\
\hline \multicolumn{8}{|l|}{$J D$} \\
\hline \multirow{2}{*}{ High frequency } & RT (m sec) & 464 & 471 & 463 & 481 & 478 & 471 \\
\hline & Errors $(\%)$ & 0 & 0 & 0 & 0 & 3 & 1.3 \\
\hline \multirow[t]{2}{*}{ Low frequency } & RT (m sec) & 459 & 472 & 487 & 496 & 496 & 482 \\
\hline & Errors $(\%)$ & 0 & 0 & 0 & 3 & 7 & 1.3 \\
\hline \multirow[t]{2}{*}{ Total } & $\mathrm{RT}(\mathrm{m} \mathrm{sec})$ & 461 & 472 & 475 & 489 & 488 & 477 \\
\hline & Errors (\%) & 0 & 0 & 0 & 1.6 & 5 & 1.3 \\
\hline
\end{tabular}

The next experiment was designed to investigate whether this putative problem with single letters could explain Madame D's word reading difficulties.

\section{Experiment 6: Word naming latencies}

As mentioned before, a recurrent problem with research on pure alexia is a failure to investigate the possible relationships between patients' performance on various, often sophisticated experimental tasks and their everyday reading problems. In most studies, it is assumed that the obtained results are causally related to word alexia. One exception to this tacit assumption was the study by Perri et al. (1996), who found a significant correlation between the types of errors made by patient SP on letter and on word reading, thus suggesting that a problem in letter reading might be causing the word dyslexia. In the present study, we wondered whether even a subtle letter identification deficit, such as the one which may underlie Madame D's problems with letters, is related to her impairment in word reading. To answer this question, we performed an analysis of reading times for words as a function of their component letters.

\section{Materials and method}

One hundred regular noun words were selected. They were divided into five groups of 20 words each. All words of each group had the same number of letters, respectively 4, 5, 6, 7 and 8 . In each group, half of the words were low-frequency words [less than 10 per million in the BRULEX data base (Content et al., 1990)] and the other half high-frequency words (more than 50 per million). All groups were matched for initial phonemes and globally for frequency.

\section{Apparatus and procedure}

Apparatus was the same as in Experiments 3-5. Words were displayed in a black, lower-case 6 point character font against a white background, in the centre of the computer screen.
Both Madame D and JD were tested. They were instructed to read each word as soon as it appeared on the screen. The target word remained visible until a vocal response was made or until $5 \mathrm{sec}$ had elapsed. Responses were followed by a 2 -sec blank screen before the next trial began. Naming latencies were measured from the onset of the word to the beginning of the response. The set of 100 words was presented three times in three different sessions. The list was divided into two blocks of 50 words. There was a resting pause after the first block. The order of the words was randomised within each block of 50 words. Before each block, five practice trials were provided, using words not included in the experimental lists.

\section{Results}

Reaction times corresponding to the production of an erroneous word (7\%), stuttering, breath, self correction (18\%) or technical malfunction $(2 \%)$ were excluded from the analyses. Mean naming latencies and errors for 4, 5, 6, 7, 8 letters words are displayed in Table 4.

\section{Analysis 1}

An ANOVA was conducted on naming latencies and errors, with items as the random variable. There were two withinsubject factors (number of letters, frequency). Separate ANOVAs were conducted for Madame D and for JD.

Madame D's latencies tended to increase as word length increased $[\mathrm{F}(4,90)=2, P=0.09]$. She named high frequency words faster than low frequency words $[1376 \mathrm{msec}$ vs. $1600 \mathrm{msec}, \mathrm{F}(1,90)=6.2, P=0.01]$. There was an interaction between length and lexical frequency $[\mathrm{F}(4,90)=2.9$, $P=0.02]$, because RTs increased with increasing length more for low frequency words (108 msec per additional letter) than for high-frequency words (22 msec per letter) (see Table 4). Accuracy was comparable for the 5 length groups $(\mathrm{F}<1)$. There were fewer errors for high-frequency words than for 
low-frequency words $[\mathrm{F}(1,90)=7.5, P=0.007]$. No semantic errors were made (see the Appendix).

JD's naming latencies increased with word length [respectively 461, 472, 475, 489, and $488 \mathrm{msec}$ for 4, 5, 6, 7, 8 letters in the words, $\mathrm{F}(4,90)=3.4, P=0.01]$. High-frequency words were named marginally faster than low-frequency words [respectively $472 \mathrm{msec}$ vs. $482 \mathrm{msec}, \mathrm{F}(1,90)=3.4, \mathrm{P}=$ 0.07]. There was no interaction between word length and frequency $(\mathrm{F}<1)$. Accuracy tended to be better for short than for long words $[\mathrm{F}(4,90)=2.3, P=0.07]$, but there was no difference for high and low frequency words, nor any interaction between length and frequency $(\mathrm{F}<1)$.

Madame D and JD demonstrated the same trend in word naming: RTs increased as the number of letters increased and RTs for high-frequency words were shorter than for lowfrequency words. Such effects are similar to those described for normal subjects in similar tasks (Eriksen et al., 1970; Klapp et al., 1973). However, a significant interaction emerged in Madame D, but not in JD, between word frequency and word length. Such an interaction (which has already been reported in groups of normal individuals; Jared and Seidenberg, 1990; Weekes, 1997) possibly failed to emerge in JD because of insufficient statistical power in a single subject. Madame D's reading disturbance may have amplified the effects, thus leading to the emergence of the interaction (see Koriat and Norman, 1985). Indeed, 17 among the 26 letter-by-letter readers reviewed by Behrmann et al. (1998), were influenced by word frequency in naming but the interaction between word length and frequency on RT was rarely mentioned (see Doctor et al., 1990; Behrmann and Shallice, 1995; Bub and Arguin, 1995, and Behrmann et al., 1998, for exceptions). The presence of a length effect for lowfrequency words and not for high-frequency words might rely on the fact that high-frequency words might evoke a lexical processing, whereas reading of low-frequency words might rely more on spelling-to-sound rules. Serial reading (as revealed by a length effect) may apply in letter-by-letter readers only when the parallel procedure fails (Howard, 1991). This presumably happens more often for rare words. Because of her reading difficulties, Madame D might have favoured the lexical procedure whenever possible.

Both the frequency effect (Kay and Hanley, 1991) and the use of a sequential procedure (Behrmann et al., 1998) are assumed to be reliable indirect indicators of access to the visual word form. This might suggest that in Madame $\mathrm{D}$ visual word form representation is relatively spared and that the primary deficit occurred at an earlier, perceptual stage.

\section{Analysis 2}

To explore the relation between the subtle letter naming deficit and the word reading difficulties shown by Madame $\mathrm{D}$, we performed several analyses of word reading times as a function of the component letters. A problem with this approach is that, presumably, Madame D often adopted a guessing strategy to overcome her reading difficulties, without always waiting until all the rightmost letters were identified (as apparently did SP; see Perri et al., 1996, p. 400). For example, she read "sublime" (sublime) instead of "subtile" (subtle), or "manche" (sleeve) instead of "manchot" (penguin). It is possible that, when a left-to-right reading strategy is used, the right part of the word contributes less to reading RT than its left part, by analogy with the cohort model proposed by Marslen-Wilson and Welsh (1978) for auditory word perception. According to this model, perception of the first $150-250 \mathrm{msec}$ of a spoken word should activate all words compatible with this onset. The pursuit of the information process should then reduce the number of word-candidates; the word is identified when the whole cohort of candidates reduces to one single word. This instant, i.e. the identification point, may itself be defined on a lexical basis by the uniqueness point (the point where a word cannot be a word other than the one it is; Marslen-Wilson, 1987). This model can be adapted to word reading by considering a spatial rather than a temporal dimension (Johnson and Pugh, 1994). The cohort of candidate words is selected on the basis of the first wickelgram (i.e. a letter-triplet) and reduced with the following wickelgrams of the word. This procedure is supposed to operate in parallel in normal subjects, but might be serial in Madame D, as suggested by the length effect.

In view of the preceding considerations, we explored Madame D's reading performance by taking into account the letter composition of the word before the uniqueness point. For example, in French the word "journal" (newspaper) has a uniqueness point after its final letter, because it could be "journalier" (daily), or "journalisme" (journalism). In contrast, the word "lectrice" (a woman reader) has its uniqueness point at the fifth letter, because after "l" "e" "c" " $t$ " " $\mathrm{r}$ " is read it can be nothing else but "lectrice". To extract a parameter reflecting the difficulty of the letters of the word, we calculated a difficulty score (D-score). Because the direct use of the sums of the RT of the letters of each word would essentially reflect the word length, the D-score was the sum of the mean RT of each letter before the uniqueness point, divided by the number of letters included in the count. The mean RT for each letter was calculated from the results of Experiment 3. For each word in the word naming experiment, we calculated a D-score. So, for example, the D-score for "lectrice" was $723 \mathrm{msec}$ [("l" $980 \mathrm{msec}+$ "e" $622 \mathrm{msec}+$ "c" $603 \mathrm{msec}+$ "t" $652 \mathrm{msec}+$ "r" $856 \mathrm{msec}) / 5$ ]. In this way, the naming difficulties specific for each letter are incorporated in the D-score; ambiguous letters will tend to increase the score and non ambiguous letters will decrease it. A regression analysis was performed between the D-score of each word and its actual mean word naming RT. Results of the regression analysis showed that word naming RTs were consistently influenced by the $\mathrm{D}$-score $\left[\mathrm{r}^{2}=0.07, \mathrm{~F}(1,98)=8, P=0.005\right]$. RTs were slower when the letters that composed the word were individually difficult to read as opposed to when they were not. A multiple regression analysis demonstrated that D-score, 
frequency, and length accounted largely for the word naming RT performance (the correlation coefficients are respectively, $0.08,-0.3,0.2$, and in the multiple regression $\mathrm{r}^{2}=0.15$, $\mathrm{F}(3,96)=5.69, P=0.0013)$.

Similar results were obtained for JD. A D-score was calculated for each word using his own results in the letter naming task (Experiment 3 ). Word naming RT were significantly influenced by the composing letters of the word: the correlation between the word naming $\mathrm{RT}$ and the $\mathrm{D}$-score was: $\mathrm{r}^{2}=0.77, \quad \mathrm{~F}(1,98)=325.06, \quad P<0.0001$. In contrast to Madame D, performance seems more influenced by the $\mathrm{D}$-score rather than by frequency and length (correlation coefficients are respectively: $0.29,-0.06$, and 0.07 ; and in the multiple regression $\left.\mathrm{r}^{2}=0.09, \mathrm{~F}(3,96)=3.10, P=0.03\right)$. This result obtained in a normal individual strengthens the conclusion that the process of letter identification influences word reading time, at least when the rarity of the word and its length encourage a (left-to-right) letter identification strategy. For Madame D, this relationship between letter and word identification implied pathological RTs for letters, and thus suggests a role of her letter identification deficit in her word reading impairment. The finding that letter reading times accounted for more variance in JD's than in Madame D's word reading performance can result from the facts that frequency and length influenced Madame D's word reading time more than JD's, and that there was greater variability of letter reading performance in Madame D than in JD.

A potential problem with these results concerns Madame D's right scotoma. The rightmost portion of the longest words could fall in the impaired part of the visual field, with consequent difficult reading, despite the partial character of the visual defect and the free exposure time. To evaluate such a concern, we made the same analysis comparing the word naming latencies and the D-score, not before the uniqueness point, but considering only the left portion of the word (half of the letters for a word with an even number of letters, and half +1 letters for words with an odd number of letters). Results showed no correlation between this particular D-score and the word RTs $(\mathrm{F}<1)$, thus suggesting that Madame D's scotoma cannot account for her word reading RTs.

\section{General discussion}

\section{Summary of the findings}

The present results suggest that a letter identification disorder influences the reading abilities of Madame $\mathrm{D}$, a pure alexic patient. A spatially-based problem seems to contribute to her performance, because left-sided letters were better processed than right-sided letters (Experiment 1). This spatial bias seemed to operate only in the horizontal dimension (Experiment 2), providing support for a left-to-right asymmetry of processing (see Rapp and Caramazza, 1991). ${ }^{6}$ On the other hand, despite her virtually faultless performance when reading letters in free vision, Madame D's reading RTs for isolated letters were slowed (Experiments 3 and 4). Furthermore, the slowest RTs were observed for letters whose identity cannot be guessed on the basis of their left part alone (Experiments 2-5), consistent with the possibility of a spatially-based deficit. The presence of these "difficult" letters in a word slowed down its reading time (when the possibility of guessing the rightmost letters of the word was taken into account; Experiment 6, analysis 2).

\section{The functional locus of impairment in Madame $D$}

Madame D's letter identification deficit increased in severity for letters which cannot be unambiguously identified on the basis of their left half. We did not have the opportunity to test the patient's knowledge of the visual form of letters in this study, but we did that after her second stroke, and found that Madame D could perfectly conjure up and manipulate mental images of letters (Bartolomeo et al., 1998a). This suggests that her letter identification deficit occurred at a perceptual level of impairment. One possible interpretation of Madame D's reading deficit could invoke a disturbed integration of spatially arranged features of letters, with left-sided features being more efficiently processed than right-sided ones, perhaps because of an early attentional orienting to this part of the letters. ${ }^{7}$ She had then to resort to high level (lexical) processes to better read the word. Word reading performance was influenced by the letter identification process and by a lexical top-down effect, which facilitates the naming of highfrequency, but not low-frequency words composed of ambiguous letters. Madame D's word reading deficit might be interpreted as a disturbance in the parallel processing of letter features, which slows down the identification of letters. This letter processing deficit, in turn, disrupts the parallel processing of letters in word reading, thus forcing the patient to rely on a serial letter identification strategy, since each letter may constitute a perceptual problem. At the word level, this serial letter identification slows RT as manifested by the word length effect. In this sense, the slowness in reading may be attributed to a degraded visual input (see Farah and Wallace, 1991; Berhmann et al., 1998).

To our knowledge, the present study is the first to demonstrate a linear relationship between letter and word naming latencies in pure alexia. Although correlation is not causation, our findings support the hypothesis that a subtle deficit in letter reading, not apparent on tasks that are not time-constrained, might impair word reading (Arguin and Bub, 1993; Perri et al., 1996; Behrmann et al., 1998).

A similar role of letter difficulty (as estimated by reading times for single letters) in word reading time was observed in JD, an individual without neurological impairment. This suggests that the parallel observation in Madame D does not result form her visual scotoma. Indeed, Warrington and Shallice (1980) showed that hemianopic patients with macular splitting do not perform like pure alexic patients and do not make errors with the right-most portion of words presented centrally. Chialant and Caramazza (1998) compared the 
performance of a right hemianopic patient with that of a letterby-letter reader and showed that the length effect was specific to alexia, despite the presence of an impairment in right hemifield performance in the hemianopic subject. Moreover, the alexic patient, but not the hemianopic one, produced errors in her normal visual hemifield analogous to the letter ambiguity effect that we observed in Madame D's left hemifield in tachistoscopic presentation (Experiment 4).

\section{Spatial or perceptual disorder?}

Our interpretation of Madame D's deficit suggests that explanations of pure alexia based on "spatial" (Rapp and Caramazza, 1991) or "perceptual" (e.g. Behrmann and Shallice, 1995) deficits are not necessarily mutually exclusive; they may, in fact, both account for the letter processing impairment that we observed. Indeed, one cannot completely exclude either the presence of a perceptual letter identification deficit in HR (Rapp and Caramazza, 1991), or the presence of a spatially determined deficit in DS (Behrmann and Shallice, 1995). HR, for whom Rapp and Caramazza hypothesise a spatial impairment, on two different occasions (Experiments 2 and 3) performed "below normal even on the first position of 7-letter strings" (p. 295). As the authors remark, "[t]his raises the possibility that processing was impaired even at initial display positions" (p. 293). This finding could be explained either by postulating that even the leftmost letter was not far enough to the left to be correctly processed, or that some other deficit was concurrently present. On the other hand, the exclusion of a spatial bias in patient DS (Behrmann and Shallice, 1995) may need further discussion. In Experiment 3 , designed to determine the extension of the attentional angle, DS had to report the initial and final letters of arrays with three to seven intervening digits. DS was more accurate with the left-sided than with the right-sided letter (p. 421), thus suggesting a left-to-right accuracy gradient (see Exp. 1 in the present study for a similar asymmetry of performance in Madame D). Similarly, as assessed in a previous study (Behrmann et al., 1990), patient DS detected more target letters in the first two positions than in the last two positions of a four-item horizontal array (p. 417).

\section{Toward a general account of pure alexia?}

The results of the present study support the notion that some differences among pure alexic patients could be quantitative, rather than qualitative, in nature (Arguin and Bub, 1993; Perri et al., 1996). Despite the virtual absence of errors in free vision reading of letters in isolation, Madame D's letter reading RTs are significantly slowed, especially for those letters whose identity cannot be unambiguously guessed on the basis of their left part alone. The fact that words containing these letters are read particularly slowly strongly suggests a relationship between the letter reading problem and alexia in
Madame D; this is similar to the relationship found in SP (Perri et al., 1996). Interestingly, SP's reading accuracy for single letters, when reanalysed on the basis of the dichotomy, proposed in the present study, between ambiguous and nonambiguous letters, mirrors the RT results obtained by Madame D. SP made $40 \%$ errors for the ambiguous letters but only $22 \%$ for the non-ambiguous letters $\left[\chi^{2}(1)=3.94, P<0.05\right]$. It is more difficult to compare Madame D's performance with that of patients described in other studies. Levine and Calvanio (1978) reported frequent confusion between Q and O, V and $\mathrm{W}$ or $\mathrm{C}$ and $\mathrm{G}$ or $\mathrm{O}$, which are predicted by our hypothesis. In the Patterson and Kay (1982) study, despite the difficulty in extracting the data from the confusion matrix of their patients (which is not totally quantitative), ambiguous letters did seem to evoke more errors than other letters. The most often confounded letters are "a or w m fl hbd p s" (not represented here exactly because typed Letraset characters are not available on our computers), which all belong, with the exception of "s", to the ambiguous group. No patient confused " $\mathrm{x}$ " or "z", which both fall in the non ambiguous group.

In conclusion, the evidence we present is consistent with interpretations of pure alexia based on a deficit in letter identification (see, e.g. Behrmann and Shallice, 1995; Perri et al., 1996). Our results also suggest that this deficit might have a directional spatial component, characterised by a leftright asymmetry of performance (see Rapp and Caramazza, 1991). Further research is needed to test the generality of this account of pure alexia, and the possible relationships of our findings with visual processing impairments not specific to reading (see Farah and Wallace, 1991).

\section{Notes}

${ }^{1}$ The choice of the term is somewhat dependent on the assumptions made about the nature of the underlying deficit. Behrmann et al. (1998) prefer the term letter-by-letter reading on the grounds that the reading disturbance is often accompanied by more general visual perceptual disorders and is not, thereby, "pure". Despite this, we still prefer to use the term 'pure alexia' because of the possibility that patients like Monsieur C (Dejerine, 1892), who was unable to read even single letters (and was not, then, a letter-by-letter reader), suffer from a deficit which only differs quantitatively, and not qualitatively, from that of letter-by-letter readers (see Perri et al., 1996).

${ }^{2}$ One possible exception could be patient MJ (Chialant and Caramazza, 1998), who made only 4 errors when reading 100 upper-case letters at 16-msec unmasked exposure. However, it is possible that the absence of masking made the task conditions insufficiently stringent to show a deficit.

${ }^{3}$ For example "Dehors, sur la terrasse, au soleil, Escartefigue, Panisse et le chauffeur qui regardent vers la droite .... (outoutside, on the terrace, in the sun, Escartefigue, Panisse and the driver looking to the right ... )" was read as "deuxième acte, non |de| hors sur |la terrasse| au soleil |escalier| Esca |rtfigue| [Paris] et le chauffeur |qu'il regarde| vers la 
droite ". Thus, there were 3 errors in 16 words (function words included) which is much more than in single word reading.

${ }^{4}$ The fact that the scotoma was not absolute, but relatively mild, may explain why the patient could name about half of the letters presented within the visual field defect.

${ }^{5} \mathrm{We}$ thank an anonymous reviewer for suggesting this analysis.

${ }^{6}$ On the basis of the present data, it is not possible to adjudge between a left-to-right processing gradient, as in HR (Rappa and Caramazza, 1991), or a step function.

${ }^{7}$ Attention is especially needed when a perceptual object is difficult to identify. This could be the case for letters in pure alexic patients. A unilateral brain lesion may bias attentional orienting towards its side (see Kinsbourne, 1993). Alternatively, left-to-right readers might show a tendency for left-toright scanning of visual material (Chokron et al., 1998). These mechanisms could lead to a better processing of the left-sided features of letters in pure alexia. Similar processes might apply at the word level, and generate left-right gradients of processing (see Rapp and Caramazza, 1991).

\section{References}

Arguin M, Bub DN. Single-character processing in a case of pure alexia. Neuropsychologia 1993; 31: 435-58.

Bartolomeo P. The novelty effect in recovered hemineglect. Cortex 1997; 33: 323-32.

Bartolomeo P, Bachoud-Lévi AC, de Gelder B, Denes G, Dalla Barba G, Brugières P, Degos TD. Multiple-domain dissociation between impaired visual perception and preserved mental imagery in a patient with bilateral exstrastriate lesions. Neuropsychologia 1998a; 36: 239-49.

Bartolomeo P, Bachoud-Lévi AC, Degos JD, Boller F. Disruption of residual reading capacity in a pure alexic patient after a mirror-image right hemispheric lesion. Neurology 1998b; 50: 286-8.

Bartolomeo P, Chokron S. Egocentric frame of reference: Its role in spatial bias after right hemisphere lesions. Neuropsychologia 1999; 37(8): 881-94.

Behrmann M, Black SE, Bub D. The evolution of pure alexia: A longitudinal study of recovery. Brain and Language 1990; 39: 405-27.

Behrmann M, Plaut DC, Nelson M. A literature review and new data supporting an interactive account of letter-by letter reading. Cognitive Neuropsychology 1998; 15: 7-51.

Behrmann M, Shallice T. Pure alexia: A nonspatial visual disorder affecting letter activation. Cognitive Neuropsychology 1995; 12: 409-54.

Benton AL, Hanney HJK, Varney NR. Visual perception of line direction in patients with unilateral brain disease. Neurology 1975; 25: 907-10.

Bub D, Arguin M. Visual word activation in pure alexia. Brain and Language 1995; 49: 77-103.

Bub DN, Black S, Howell J. Word recognition and orthographic context effects in a letter-by-letter reader. Brain and Language 1989; 36: 357-76.

Caramazza A, Hillis A. Levels of representation, co-ordinate frames, and unilateral neglect. Cognitive Neuropsychology 1990; 7: 327-59.

Chialant D, Caramazza A. Perceptual and lexical factors in a case of letter-byletter reading. Cognitive Neuropsychology 1998; 1/2: 167-201.

Chokron S, Bartolomeo P, Perenin MT, Helft G, Imbert M. Scanning direction and line bisection: A study of normal subjects and unilateral neglect patients with opposite reading habits. Cognitive Brain Research 1998; 7(2): 173-8.

Content A, Mousty P, Radeau M. Brulex, une base de données lexicales informatisée pour le français écrit et parlé. L'Année Psychologique 1990; 90: 551-66.

Déjerine MJ. Contribution à l'étude anatomo-pathologique et clinique des différentes variétés de cécité verbale. II - cécité verbale pure avec intégrité de l'écriture spontanée et sous dictée. Mémoires de la société de biologie $1892 ; 61-90$
Deloche G, Hannequin D, Dordain M, Perrier D, Pichard B, Quint S, MetzLutz MN, Kremin H, Cardebat D. Picture confrontation oral naming: Performance differences between aphasics and normals. Brain and Language 1996; 53: 105-20.

Doctor EA, Sartori G, Saling MM. A letter-by-letter reader who could not read nonwords. Cortex 1990; 26: 247-62.

Eriksen CW, Pollock MD, Montague WE. Implicit speech: Mechanisms in perceptual encoding? Journal of Experimental Psychology 1970; 84: 502-7.

Farah MJ, Wallace MA. Pure alexia as a visual impairment: A reconsideration. Cognitive Neuropsychology 1991; 8: 313-34.

Friedman RB. Acquired alexia. In: Boller F, Grafman J, editors. Handbook of neuropsychology, Vol. 1. Amsterdam: Elsevier, 1988: 377-91.

Howard D. Letter-by-letter readers: Evidence for parallel processing. In: Besner D, Humphreys GW, editors. Basic processes in reading: Visual word recognition. Hillsdale, NJ: Lawrence Erlbaum Associates, 1991: 34-76.

Jared D, Seidenberg MS. Naming multisyllabic words. Journal of Experimental Psychology: Human Perception and Performance 1990; 16: 92-105.

Johnson NF, Pugh KR. A cohort model of visual word recognition. Cognitive Psychology 1994; 26: 240-346.

Johnston JC, McClelland J. Experimental tests of a hierarchical model of word identification. Journal of Verbal Learning and Verbal Behavior 1980; 19: 503-24.

Kay J, Hanley R. Simultaneous form perception and serial letter recognition in a case of letter-by-letter reading. Cognitive Neuropsychology 1991; 8: 249-73.

Kinsbourne M. Orientational bias model of unilateral neglect: Evidence from attentional gradients within hemispace. In: Robertson IH, Marshall JC, editors. Unilateral Neglect: Clinical and experimental studies. Hove (UK): Lawrence Erlbaum Associates, 1993: 63-86.

Kinsbourne M, Warrington EK. A disorder of simultaneous form perception. Brain 1962; 85: 461-86.

Klapp ST, Anderson WG, Berrian RW. Implicit speech in reading, reconsidered. Journal of Experimental Psychology 1973; 100: 368-74.

Kolers PA. Clues to a letter's recognition: Implications for the design of characters. Journal of Typographic Research (now Visible Language) 1969; 3: $145-68$.

Koriat A, Norman J. Reading rotated words. Journal of Experimental Psychology: Human Perception and Performance 1985; 11: 490-508.

Levine DN, Calvanio R. A study of the visual defect in verbal alexiasimultanagnosia. Brain 1978; 101: 65-81.

Marslen-Wilson WD. Functional parallelism in spoken word recognition. Cognition 1987; 71-102.

Marslen-Wilson WD, Welsh A. Processing interactions and lexical access during word recognition in continuous speech. Cognitive Psychology 1978; 29-63.

McClelland JL, Rumelhart DE. An interactive activation model of context effects in letter preception: Part 1. An account of basic findings. Psychological Review 1981; 88: 375-407.

Pallier C, Dupoux E, Jeannin X. Expe: An expandable programming language for on-line psychological experiments. Behavior Research Methods, Instruments and Computers 1997; 29: 322-7.

Patterson K, Kay J. Letter-by-letter reading: Psychological description of a neurological syndrome. The Quarterly Journal of Experimental Psychology 1982; 34A: 411-41.

Perri R, Bartolomeo P, Silveri MC. Letter dyslexia in a letter-by-letter reader Brain and Language 1996; 53: 390-407.

Rapp BC, Caramazza A. Spatially determined deficits in letter and word processing. Cognitive Neuropsychology 1991; 8: 275-311.

Raven JC, Court JH, Raven J. Manual for the Raven's progressive matrices and vocabulary scales. Los Angeles: Western Psychological Services, 1978.

Reuter-Lorenz PA, Brunn JL. A prelexical basis for letter-by-letter reading: A case study. Cognitive Neuropsychology 1990; 7: 1-20.

Rumelhart D, McClelland JL. An interactive activation model of context effects in letter perception. Part 2. This contextual enhancement effect and some tests and extensions of the model. Psychological Review 1982; 89: $60-94$.

Shallice T. From neuropsychology to mental structure. New York: Cambridge University Press; 1988.

Warrington EK, James M. The visual object and space perception battery. Bury St Edmunds: Thames Valley Test Company, 1991. 
Warrington EK, Shallice T. Word-form dyslexia. Brain 1980; 103: 99-112. Wechsler D. Wechsler Adult Intelligence Scale - Revised Manual. New York: Psychological Corporation, 1981.

Weekes BS. Differential effects of number of letters on word and nonword naming latencies. Quaterly Journal of Experimental Psychology 1997; 50A: $439-56$.

Received on 19 December, 2001; resubmitted on 20 June, 2002; accepted on 23 September, 2002

\section{Appendix. List of Madame D's errors in the word naming task (Experiment 6)}

\begin{tabular}{ll}
\hline Target & Response \\
\hline ramure [branches] & rainure [channel] \\
maison [house] & son [sound] \\
tondeuse [lawn mower] & tondu [mown], tombeau [tomb] \\
saleté [dirtiness] & salade [salad] \\
bouc [goat] & bout [extremity] \\
banquise [ice floe] & banque [bank] \\
grade [rank] & grande [tall] \\
écharpe [scarf] & échapper [escape] \\
cumin [cummin] & /kymil/ \\
nain [dwarf] & nez [nose] \\
nomade [nomads] & /no/ \\
paprika [paprika] & prika \\
fuseau [spindle] & fusée [rocket] \\
activité [activity] & /ak/ \\
destin [destiny] & destine [destine] \\
grue [crane] & gai [happy] \\
jeunesse [youth] & jeune [young] \\
noirceur [darkness] & /nüa/ \\
rascasse [scorpion fish] & /ras/ \\
série [series] & cira [waxed] \\
virus [virus] & virtuel [potential] \\
\hline
\end{tabular}




\title{
Mechanisms of pure alexia: spatially based impairment, letter identification deficit, or both?
}

\section{Anne-Catherine Bachoud-Lévi and Paolo Bartolomeo}

\begin{abstract}
We studied reading performance for words and for isolated letters in a pure alexic patient. She performed reasonably well when naming isolated letters but was slower in reading letters than a control subject when reaction times (RTs) were recorded. When the patient read isolated letters, RTs were slower for a subset of letters that cannot be recognized from their left part alone (e.g. "b", an ambiguous letter, could be read "b" "h" "l" or "k" whereas "a" has no predictable confounders). We observed a significant positive correlation between the RTs for reading a word and the mean RTs for reading each of its composing letters before its uniqueness point (i.e. the point, when reading from the left to the right, where a word cannot be a word other than the one it is). This result suggests that, in our patient, the letter identification deficit can account for the slow, letter-by-letter reading behaviour insofar as each letter represents a perceptual problem. Our findings can be accounted for by a deficit in the parallel processing of the left and right parts of each letter, compounded with a bias to process first the left part of the letter, and may thus reconcile the hypotheses of spatially-based deficit (Rapp and Caramazza, 1991) and of a perceptual deficit occurring at the letter identification level (Behrmann and Shallice, 1995; Perri et al., 1996).
\end{abstract}

Journal

Neurocase 2003; 9: 164-176

Neurocase Reference Number:

\#499/01

\section{Primary diagnosis of interest}

Pure Alexia

\section{Author's designation of case}

Madame D

\section{Key theoretical issue}

- A deficit in the parallel processing of the left and right parts of each letter, compounded with a bias to process first the left part of the letter, may account for word reading in pure alexia.

Key words: word reading; letter identification; spatially-based impairment

\section{Scan, EEG and related measures}

CT scan, MRI

\section{Standardized assessment}

DO80 (Deloche et al., 1996), Visual Object and Space Perception Battery (Warrington and James, 1991), Judgement of Line Orientation Task (Benton et al., 1975), Raven Progressive Coloured Matrices (Raven et al., 1978), WAIS-R (Wechsler, 1981), Wechsler Memory scale, digit span

\section{Other assessment}

Neglect battery (Bartolomeo and Chokron, 1999), Naming latencies for words and isolated letters

\section{Lesion location}

- Left temporo-occipital

Lesion type

Haematoma

\section{Language}

English 